\title{
Layout Optimization of Gas Compression Station Equipment with Branch and Bound Algorithm
}

\author{
Farizal*, Reno Wibawanto, RahmatNurcahyo \\ Department of Industrial Engineering, Faculty of Engineering, Universitas Indonesia, Depok 16424, Indonesia \\ *Corresponding author: farizal@eng.ui.ac.id
}

\begin{abstract}
The arrangement of process equipment and buildings can have a big impact on efficiency of a plant. In an effort to maximize plant efficiency, the plant's layout design should facilitate the production process, minimize the material process flow and operating costs, and still meet the safety and security aspects of the operation. This research is about optimizing a gas compression station equipment layout. For the purpose, an MINLP model was developed and solved by with Branch and Bound Algorithm. The model takes into consideration factors of safety distance and wind direction consideration due to Flare Stack position to minimize material flow costs. The result showed that the optimized layout is different with the existing layout. The optimized layout can achieve up to $21.6 \%$ cost less than the reference one.
\end{abstract}

Key words: Gas Compression Station, MINLP, Branch and Bound, Layout Optimization.

\section{INTRODUCTION}

According to Champbell\& Price [1] in the next century, back bone of energy source will shift from fossil fuels, i.e. oil and coal to gas before they later shift to renewable sources such as solar, wind, ocean, etc. Several reasons push this shifting; i.e. energy scarcity, environment reason, and technology maturity and readiness. Oil and coal will be depleted in the near future, assuming there is no new deposits found and no technology breakthrough. The oil and coal reserve are fix since they were formed naturally long time ago. They production will be decrease in the future $[2,3]$.

Even though current technology is capable to unlock difficult reserve so that global oil reserves will almost double by 2050 [4], but oil and coal are notoriously environmentally unfriendly [5]. Renewable energy sources are abundant and they are green. However, to replace a well establish current fossil fuels, RE needs more time to be established. On the other side, gas resource is quite big, the technology is ready since the technology is not that different with fossil fuel technologies, and gas is much greener than fossil fuels [6].
Even gas, in form of methane gas, is renewable since it is a by-product of municipal solid waste and biomass decomposition [7]. To make gas more ready, research on gas system technology is carried out here. Investigation about gas and its application are found in some references [8-10].

As a primer energy source taken from the earth, gas well is usually far away from the area it is needed. To deliver the gas, most of the time through pipeline, it should be compressed and pressurized at gas compression station. The composition process and building equipment may have a major impact on the efficiency of the plant. To maximize plant efficiency, the plant layout design should facilitate the production process, minimize material process flow and operating costs, and optimize the utilization of labor.

According to Jung [11], the development of the overall layout must consider the safety as well as providing support for the operation and maintenance. The layout should also consider the scope for future expansion as well as access to the installation, i.e. constructability, and prevent job redesigns. Diaz-Ovalle et al.[12] proposed an approach to solve the facility layout problem with worst case scenario of toxic release when calm wind and stable atmospheric occur.

Previous studies that integrate security in the plant layout optimization have been partially reported. Penteado \& Ciric [13] developed a layout model that takes into account the financial risks and protection devices and assumes that the ground occupied by each unit is marked with a circle trace. This model was further evaluated with a rectangular area and combine Dow's Fire and Explosion Index (F \& EI) as an analytical tool to evaluate the risk of the new plant and existing plant. While Patsiatzis [14] studied layout design methodology with consideration of the risk of an accident through Dow's Fire and Explosion Index.

Methodology Branch and Bound algorithm was proposed to optimize the layout. Other researchers have focused on evaluating the risk of design layout of specific cases at the conceptual level. Medina-Herrera et al. [15] developed facility layout model considering Quantitative Risk Analysis (QRA) A more recent study on safety and risk of a plant was conducted by Farizal, et al. [16] They proposed an optimized model that taking into consideration of toxic gas dispersion when designing layout of a geothermal power plant. 
Several other studies related to the optimization of chemical plant layout such as human risk modeling of process equipment were assessed as individual risk and then converted to safe distance. A study based on the safe distance and minimum distance required for design operation, risk zone and maintenance zone around of the process equipment conducted by Han et al. [17]. Meanwhile Martinez-Gomez, et al. [18] proposed optimization formulation for optimal facility layout for installation and reallocation of facilities (office buildings and control rooms) through multi-year time frames involving future expansion of the plant. The proposed optimization formulation is a multi-purpose model optimization in combination with quantitative risk analysis (QRA). Caputo et al. [19] focused on the effectiveness of genetic algorithm for the completion of the MILP model on plant layout issues with pipeline cost constraints, pumping costs, safety costs, and land costs. Alves et al [20], optimized chemical plant layout with minimizing risk to general public. They used Monte Carlo method to superposition of the accident effect areas and solved their model with Simulated Annealing. Park et al. [21], developed a model of multi-floor plant layout with safety distance consideration using mixed integer linear programming, while $\mathrm{Wu} \&$ Wang [22] optimized the flow of the steam pipes for a large-scale plant layout.

According to the regulation of the IRI (Industrial Risk Insurers) IM.2.5.2 [23], several aspects are needed to be considered when designing the layout and spacing facility equipment such as high-risk operations, grouping operations, dependence between operations, exposure to fire and explosion, access for maintenance and emergencies, potential natural disasters and climate, future expansion, etc. It is also explained that the process plant must be equipped with a street adjacent to the process unit, a unit of utility, material-handling and loading areas, and a group of off-site equipment that require access for maintenance and fire-fighting.

Uncontrollable factors to consider such as the slope of the land, climate, exposure to natural disasters, the direction and strength of the wind. Placing a source of fire against the wind direction from a potential steam leak or placing a descending tank from an essential unit may reduce the potential loss from an explosion or fire. According to Smith \&Botermans [24], attention should be given to the general appearance of a plant. The layout of buildings, structures, and equipment groups should be neat, symmetrical, balanced, consistently keeping the pipeline as short as possible.

Plant layout problem, in general, which is compiled with MILP/MINLP model with safety considerations and/or cost as the main constraint function and some additional variables on constraint function have been investigated. However, wind direction factor that influences fire source (flare stack direction and furnaces) and flare safety factor that accordance with the recommendations of IM.2.5.2 IRI have not been taken into consideration to the existing model. Function of order equipment and plant neatness and symmetry that allow ease of access during operation and maintenance have also not been studied. For the purpose, the model on this research was developed with MINLP. The model then solved using Branch and Bound Algorithm.

\section{METHODOLOGY}

A compression gas station (SKG) is located in RantauPanjang, $59 \mathrm{~km}$ from Lhoksukon. Due to this long distance, RantauPanjangSKG gas should be recompressed to maintain pressurized conditions. The gas will be treated through Suction Scrubber to ensure it is free from any liquid before entering the gas compressor. The release gas from the compressor is then cooled by Cooler. After that it goes to Discharge Scrubber to remove any remaining fluids before it is transferred through the pipe. The gas from the compressor will continue to flow in a newly constructed 24 -inch pipeline to Brandan base for $165 \mathrm{~km}$. This research will be focused on equipment layout of RantauPanjang gas compression station.

The gas compressor system is composed by some pipes and instrumentations. It's role is to make sure that the gas passing through will remain in the proper pressure. In brief, the process flow is first the gas enters the SKG Pig Receiver which serves to receive a pig from Arun during initial start-up conditions or during pigging. Slug Catcher serves to separate the condensate/slug creates during pipeline transportation of the gas from Arun to Belawan. Suction Scrubber serves to separate condensate and impurity particles contained in the gas before the gas pressure is increased in the Gas Booster Compressor.

Gas Booster Compressor serves to raise the gas pressure to be able to flow to the Pangkalan Brandan. Air Cooler cools the temperature after the gas goes out of the Gas Booster Compressor. Discharge Scrubber serves to separate the condensate liquid and particulate impurities that might be formed during the gas compression process.

The gas is scrubbed before it is passed through the pipeline. Pig Pig launcher is functioned to launch the gas into the next station during pigging conditions. Between the process equipment units require a connecting pipe which has a specific diameter dimension and planned length. Figure 1 shows the existing plant layout.

As stated in the standard IM 2.5.2 IRI, when designing a SKG layout, wind direction data is needed for planning the laying of direct fired equipment, which in this gas compression station is flare stack. To be safe, direct-fired equipment should be separated at a specific distance from other areas and the location should be of the dominant direction of the wind.

In this study, pipeline cost data is required. It is put as a coefficient in the objective function of the model. The objective function itself is to minimize the total cost, keeping 
in mind the safe distance between each equipment. Safety distance is calculated based on the regulation of IRI IM.2.5.2. The distance format is in the form of the safety standard matrix calculated according to the rules. The standard arranged will dictate the distance between equipment units.

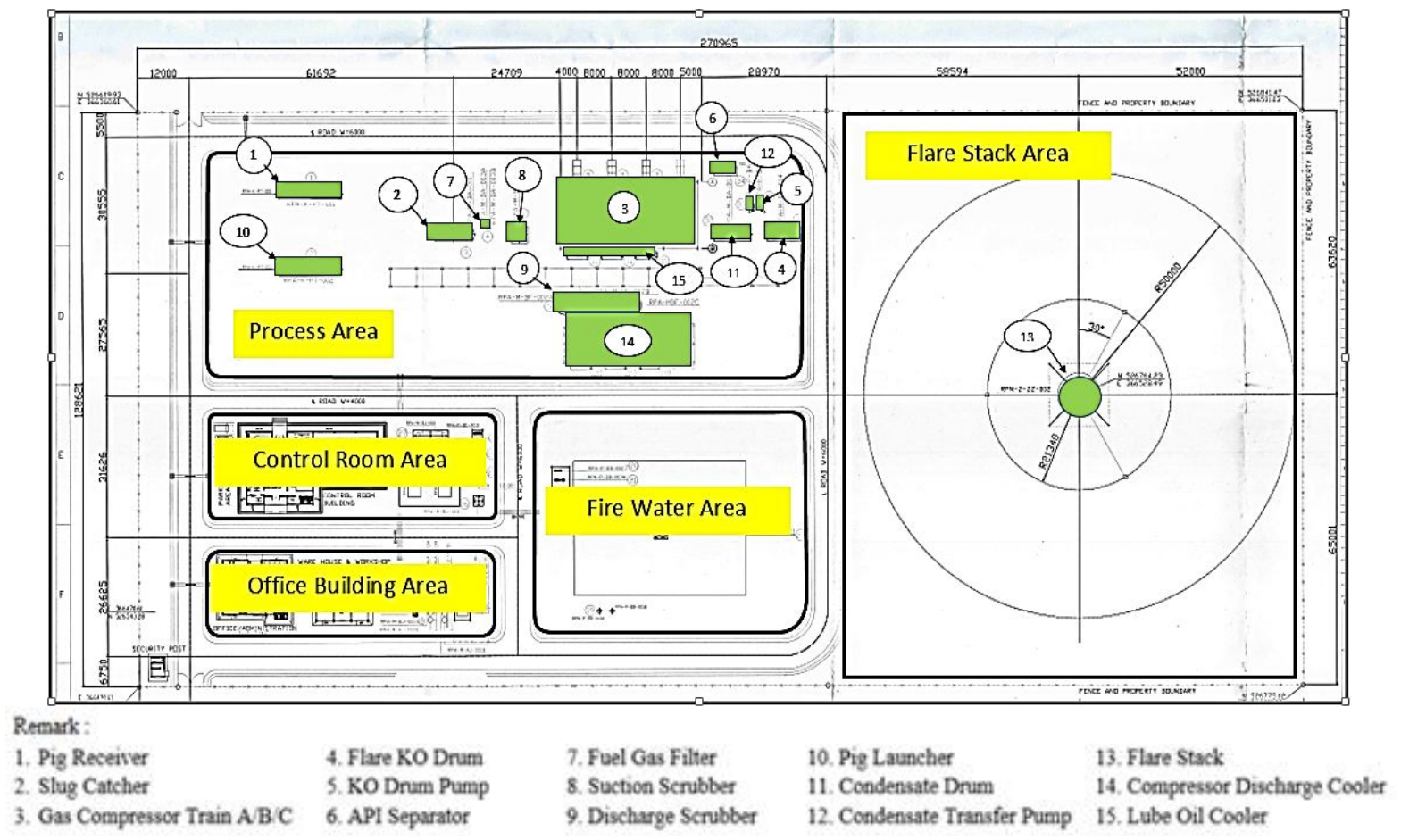

Figure 1:. Existing gas compression station layout

This study uses mixed integer non-linear programming (MINLP) model to obtain the layout of gas compression station. The model takes into account the land area, wind direction, and the safety distance guidelines fulfillment. The model is formulated as follows:

Index $\mathrm{i}=$ unit of equipment, $\mathrm{i}=1,2, \ldots 15$

Parameter

$\mathrm{x}^{\max }=$ maximum $\mathrm{x}$-coordinate

$y^{\max }=$ maximum y coordinates

li $=$ length of equipment $\mathrm{i}$

wi $=$ width of equipment $\mathrm{i}$

$\mathrm{L}_{\mathrm{ij}}=\mathrm{a}$ safe distance between the equipment $\mathrm{i}$ and $\mathrm{j}$ that required

$\mathrm{D}_{\mathrm{ij}}=$ total distance required between equipment $\mathrm{i}$ and $\mathrm{j}$

$\mathrm{C}_{\mathrm{ij}}=$ the price of pipe that connect equipment $\mathrm{i}$ to equipment $\mathrm{j}$

per meter

Decision variable

$\mathrm{xi}, \mathrm{yi}=$ coordinates of the geometric center of unit $\mathrm{i}$

Complete mathematics model:

$$
\operatorname{Min} Z=\sum_{i=1}^{15} \sum_{j \neq i}^{15} C_{i j} D_{i j}
$$

Subject to
Equation (1) is the objective function of the model which is minimizing the total cost distance between equipment $\mathrm{i}$ to equipment $j$ of all parts on the SKG plant. For RantauPanjang compression station, it has 15 units to be considered. They are Pig Receiver, Slug Catcher, Fuel Gas Filler, Suction Scrubber, Condensate Drum, Gas Compressor, Discharge Scrubber, Flare Stack, Pig Launcher, Condensate Transfer Pump, Flare KO Drum, KO Drum Pump, API Separator, and Lube Oil Cooler (see Figure 1). To achieve the objective, the layout should comply 9 restrictions (equations $2-10$ ).

Equations (2) and (3) are about distance restriction between centers of two units $i$ and $j$. In this study the distance was calculated using rectilinear distance. The distances on these 
equations are already accommodating safe distance between two equipments. Equations (4) and (5) are space availability restriction. Each unit coordinates should not exceed the current existing gas station.

Equation (6) will push the units arranged symmetrically and neatly; the isle is straight. Equations (7) and (8) will make sure that there will be no overlap between one unit with the adjacent one both in horizontal and vertical directions. Equation (9) is used to assign a certain unit to a specific spot. This constraint can be used for instance to put the flare stack at a pre defined location. The last equation, Equation (10) is the non negativity constraints. This equation is an integral part of any optimization model. It is used to make sure that the solution results are positive values.

The SKG has $34,852 \mathrm{~m}^{2}$ area wide. As clearly shows on Figure 1, the plant consists of five major areas which are process area, control room area, office building area, fire water area, and flare stack area. This study is focused on process area and flare stack area. Those areas are $10,265 \mathrm{~m}^{2}$ and $24,587 \mathrm{~m}^{2}$, respectively. Wind speed and direction data are needed for determining direct fires equipment spot that agrees to IRI IM 2.5.2 standard. The data for the year of 2017 is tabulated on Table 1. Data was collected from Freemeteo [25]. Table 1 clearly shows that the wind was blown toward south to west.

Table 1: Wind speed and direction at RantauPanjang

\begin{tabular}{|l|c|c|}
\hline \multirow{2}{*}{ Month } & \multicolumn{2}{|c|}{ Wind } \\
\cline { 2 - 3 } & Direction & Speed $(\mathrm{km} / \mathrm{h})$ \\
\hline January & West & 17 \\
February & South & 22 \\
March & South & 22 \\
April & South & 15 \\
May & South & 19 \\
June & Southwest & 17 \\
July & West & 22 \\
August & West & 15 \\
September & Southwest & 17 \\
October & South & 13 \\
November & Southwest & 13 \\
December & South & 19 \\
\hline
\end{tabular}

Minimum distance between 2 equipments was calculated based on IRI IM 2.5.2 regulation. The results are presented on Table 2.

\section{RESULTS}

The model developed in this study was solved using Branch and Bound Algorithm. The algorithm was coded on LINGO 11.0 and run on a computer with Intel ${ }^{\circledR}$ Celeron ${ }^{\circledR}$ Processor N3060. After verification and validation, the results of the program are the coordinates (x, y) of 15 equipments with the actual object scale. From the coordinates of each of the equipment, the layout was plotted with AutoCAD software. Figure 2 shows the proposed area layout.
Table 3 clearly shows that all the optimization distance results between the equipments are fulfilling safety standard while the existing layout has some distances that violated the standard (indicated with yellow color background). Considering Flare Stack position that accordance with wind blowing direction, based on wind direction data displayed on Table 1), the existing Flare Stack spot is located on the east side which conforms with the standard recommendation (at least within $91 \mathrm{~m}$ apart).

However, some parts on the existing station have distance less than the standard. Table 4 lists piping costs and length for each "from-to" equipments. While all the distance between 2 equipments on proposed layout are fulfilling the required safety standard, the optimized layout total cost is less than total cost of existing layout. The existing piping total cost of current gas station is 502,421,088.00 IDR, while the total cost of optimization piping is $393,887,000.00$ IDR. The proposed model achieved efficiency of $21.6 \%$.

\section{CONCLUSION}

Based on the calculation results and the analysis, it is concluded that mixed integer non-linear programming model developed has provided output of process compressed gas station new layout area that meets safety distance standard between equipments and the dominant wind direction for the laying of a flare stack. The model developed, thus, can be used by layout plant designer in the early stages of layout planning to meet the aspect of cost, compliance guidelines for safe distance, wind direction and accessibility. From the cost aspect, the optimization of Gas Compression Station layout can reduce total pipeline cost by $21.6 \%$.

\section{REFERENCES}

1. K.M. Campbell,\&J. Price (2008), The global politics of energy, eds. The Aspen Institute

2. M. Hook (2009). Depletion and Decline Curve Analysis in Crude Oil Production. Unpublished thesis. Departmentfor Physics and Astronomy, Uppsala University.

3. D. Rutledge (2011). Estimating long-term world coal production with logit and probit transforms. International Journal of Coal Geology. 85, 23 - 33. https://doi.org/10.1016/j.coal.2010.10.012

4. Reuters (2015), https://www.telegraph.co.uk/finance/newsbysector/energ y/oilandgas/11971280/The-Earth-is-not-running-out-ofoil-and-gas-BP-says.html retrieve on December 21, 2019

5. M. Denchak (2018). Fossil fuels: the dirty facts. NRDC https://www.nrdc.org/stories/fossil-fuels-dirty-facts retrieve on December 21, 2019

6. R.A. Hefner III (2002). The age of energy gases. International Journal of Hydrogen Energy. 27, 1, 1 - 9. https://doi.org/10.1016/S0360-3199(01)00079-9

7. Farizal, A. Zulys, Kh. Ihwan, I. Prihastuti, S. Yulianda\&E. Dissa (2014). Sanitary Landfill Gas for 
Farizal et al., International Journal of Emerging Trends in Engineering Research, 8(6), June 2020, 2465 - 2471

Riau Rural Electricity. Project report submitted to EEP (Energy and Environment Partnership) with Indonesia

8. L.V. Gunawan, M. Effendy (2020). Engine Performance and Exhaust Gas Emission of a Gasoline Engine using Ethanol-Gasoline Blendedfrom Bioethanol of DurioZibethinusSeed and SalaccaZalacca. International Journal of Emerging Trends in Engineering Research, 8(4), 1129-1134. https://doi.org/10.30534/ijeter/2020/29842020

9. M.Sridhar, M. Ravi Kumar, J.Chandana, S.V.Pranitha, K.Y.Sahithi and Chella Santhosh. (2020) Detection of Various Adulterants Concentration levels in Gasoline Using NI-LAB VIEW, International Journal of Emerging Trends in Engineering Research, 8(4), 1247 - 1250. https://doi.org/10.30534/ijeter/2020/49842020

10. Alexey FedorovichBurkov, Victor Viktorovich Mikhanoshin and Wagarshak Radikovich Avetisyan. (2020) Improving the Energy Efficiency of PropulsionSystems of the Sea and River Fleets, International Journal of Emerging Trends in Engineering Research, 8(4), 1170 - 1174. https://doi.org/10.30534/ijeter/2020/35842020

11. S. Jung (2010). Facility sitting and layout optimization based on process safety. College Station, TX: Texas A \& M University.

12. C. Diaz-Ovalle, R. Vazquez-Roman \& M.S. Mannan (2010). An approach to solve the facility layout problem based on the worst-case scenario. Journal of Loss Prevention in the Process Industries 23, 3, 385-392

13. F.D. Penteado\&A.R. Ciric (1996). An MINLP approach for safe process plant layout, IndEngChem Res, 35, 4, 1354-1361. https://doi.org/10.1021/ie9502547

14. D.I. Patsiatzis, G. Knight, L.G. Papageorgiou (2004). An MILP Approach to Safe Process Plant Layout. Chemical Engineering Research and Design, 82, 5, 579-586.

15. K. Medina-Herrera, K., Jimenez-Gutierrez, A., \& Grossman, I. E. (2014). A mathematical programming model for optimal layout considering quantitative risk analysis. Computers and Chemical Engineering, 68, 165-181.

16. Farizal, D. Ariva, M. Achyar\&A. Rahman (2018). Geothermal power plant are layout optimization considering toxic gas dispersion. Proceeding of International Conference on Engineering Technology and Applied Sciences (ICETAS 2018).

https://ieeexplore.ieee.org/stamp/stamp.jsp?tp=\&arnumb er $=8629199$

https://doi.org/10.1109/ICETAS.2018.8629199

17. K. Han, S. Cho \&E.S. Yoon (2013). Optimal layout of a chemical process plant to minimize the risk to humans. Proc. Comput. Sci. 22, 1146-1155.

18. J. Martinez-Gomez, F. Nápoles-Rivera, J.M. Ponce-Ortega, M. Serna-González, \&M.M. El-Halwagi (2015). Optimization of facility location and reallocation in an industrial plant through a multi-annual framework accounting for economic and safety issues. Journal of Loss Prevention in the Process Industries, 33, 129-139. https://doi.org/10.1016/j.jlp.2014.11.021

19. A.C. Caputo, P.M. Pelagagge, M. Palumbo\&P. Salini (2015). Safety-based process plant layout using genetic algorithm. Journal of Loss Prevention in the Process Industries, 34, 11, 139-150.

20. D.T.S. Alves, J.L. de Medeiros, \& O.Q.F. Araujo (2016). Optimal determination of chemical plant layout via minimization risk to general public using Monte Carlo and Simulated Annealing techniques, Journal of Loss Prevention and the Process Industries 41, 202-214

21. K. Park, J. Koo, D. Shin, C.J. Lee \&E.S. Yoon (2011). Optimal multi-floor plant layout with consideration of safety distance based on mathematical programming and modified consequence analysis. Korean Journal of Chemical Engineering 28, 1009-1018.

22. Y. Wu\&Y. Wang (2017). A chemical industry area-wide layout design methodology for piping implementation. Chemical Engineering Research and Design, 118, 2, 81-93. https://doi.org/10.1016/j.cherd.2016.12.005

23. IRI (1996). IRI IM.2.5.20il and Chemical Plant Layout and Spacing. Connecticut: Author.

24. Smith, P., \&Botermans, R. (2008). Process piping design handbook. Houston, TX: Gulf Pub.

25. Freemeteo (2017) http://www.freemeteo.co.id/mobile/cuaca/ 
Farizal et al., International Journal of Emerging Trends in Engineering Research, 8(6), June 2020, 2465 - 2471

Table 2:. Distance between equipment

\begin{tabular}{|c|c|c|c|c|c|c|c|c|c|c|c|c|c|c|c|c|}
\hline \multicolumn{2}{|c|}{ From-To $(\mathrm{m})$} & 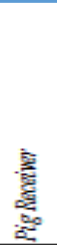 & 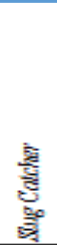 & 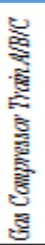 & 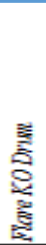 & 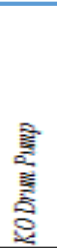 & 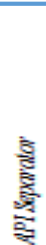 & 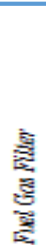 & 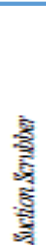 & 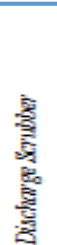 & 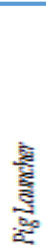 & 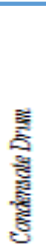 & 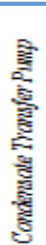 & 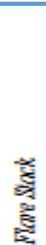 & 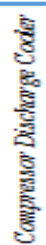 & 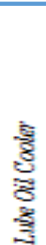 \\
\hline 1 & Pig Receriver & & 5 & 15 & 5 & 3 & 5 & 5 & 5 & 5 & 5 & 5 & 5 & 91 & 5 & 3 \\
\hline 2 & Slug Carcher & 5 & & 15 & 5 & 3 & 5 & 5 & 5 & 5 & 5 & 5 & 5 & 91 & 5 & 3 \\
\hline 3 & $\begin{array}{l}\text { Gas Compressor Train } \\
A B / C\end{array}$ & 15 & 15 & & 15 & 9 & 15 & 15 & 15 & 15 & 15 & 15 & 15 & 91 & 9 & 9 \\
\hline 4 & Flare KO Drwm & 5 & 5 & 15 & & 3 & 5 & 5 & 5 & 5 & 5 & 5 & 5 & 91 & 5 & 3 \\
\hline 5 & KO Drwm Pwmp & 3 & 3 & 9 & 3 & & 3 & 3 & 3 & 3 & 3 & 3 & 2 & 91 & 5 & 3 \\
\hline 6 & API Separator & 5 & 5 & 15 & 5 & 3 & & 5 & 5 & 5 & 5 & 5 & 5 & 91 & 5 & 3 \\
\hline 7 & Fwel Gar Filter & 5 & 5 & 15 & 5 & 3 & 5 & & 5 & 5 & 5 & 5 & 5 & 91 & 5 & 3 \\
\hline 8 & Suction Scrubber & 5 & 5 & 15 & 5 & 3 & 5 & 5 & & 5 & 5 & 5 & 5 & 91 & 5 & 3 \\
\hline 9 & Discharge Scrubber & 5 & 5 & 15 & 5 & 3 & 5 & 5 & 5 & & 5 & 5 & 5 & 91 & 5 & 3 \\
\hline 10 & Pig Lawncher & 5 & 5 & 15 & 5 & 3 & 5 & 5 & 5 & 5 & & 5 & 5 & 91 & 5 & 3 \\
\hline 11 & Condensate Drwm & 5 & 5 & 15 & 5 & 3 & 5 & 5 & 5 & 5 & 5 & & 5 & 91 & 5 & 3 \\
\hline 12 & $\begin{array}{l}\text { Condensate Transfer } \\
\text { Pungy }\end{array}$ & 5 & 5 & 15 & 5 & 2 & 5 & 5 & 5 & 5 & 5 & 5 & & 91 & 5 & 5 \\
\hline 13 & Flare Stack & 91 & 91 & 91 & 91 & 91 & 91 & 91 & 91 & 91 & 91 & 91 & 91 & & 91 & 91 \\
\hline 14 & $\begin{array}{l}\text { Compressor Discharge } \\
\text { Cooler }\end{array}$ & 5 & 5 & 9 & 5 & 5 & 5 & 5 & 5 & 5 & 5 & 5 & 5 & 91 & & 5 \\
\hline 15 & Lube Oil Cooler & 3 & 3 & 9 & 3 & 3 & 3 & 3 & 3 & 3 & 3 & 3 & 5 & 91 & 5 & \\
\hline
\end{tabular}

Tabel 3:Distance between gas compression unit

\begin{tabular}{|l|l|c|c|c|}
\hline \multicolumn{2}{|c|}{ Unit } & \multicolumn{3}{c|}{ Distance (m) } \\
\hline \multicolumn{1}{|c|}{ From } & \multicolumn{1}{c|}{ To } & $\begin{array}{c}\text { Safety } \\
\text { Standard }\end{array}$ & Existing & $\begin{array}{c}\text { Optimization } \\
\text { Result (m) }\end{array}$ \\
\hline Pig Receiver & Slug Catcher & 5 & 21.7 & 6.7 \\
\hline Slug Catcher & Fuel Gas Filter & 5 & 3.6 & 5.1 \\
\hline Slug Catcher & Suction Scrubber & 5 & 8.7 & 6.6 \\
\hline Slug Catcher & Condensate Drum & 5 & 55 & 10.5 \\
\hline Gas Compressor & Suction Scrubber & 15 & 8.2 & 15 \\
\hline Gas Compressor & Discharge Scrubber & 15 & 12.2 & 18 \\
\hline Gas Compressor & Flare Stack & 91 & 94 & 106 \\
\hline Discharge Scrubber & Pig Launcher & 5 & 51 & 27.3 \\
\hline Suction Scrubber & Condensate Drum & 5 & 44 & 10.7 \\
\hline Condensate Drum & Condensate Transfer Pump & 5 & 3.3 & 12.7 \\
\hline Condensate Drum & Flare Stack & 91 & 83.7 & 148.7 \\
\hline Discharge Scrubber & Condensate Drum & 5 & 13.7 & 5.1 \\
\hline Flare Stack & Pig Receiver & 91 & 184.3 & 184 \\
\hline Flare Stack & Slug Catcher & 91 & 149.9 & 177 \\
\hline Flare Stack & Flare KO Drum & 91 & 77.6 & 161 \\
\hline Flare Stack & KO Drum Pump & 91 & 85 & 162.4 \\
\hline Flare Stack & API Separator & 91 & 96.4 & 159.4 \\
\hline Flare Stack & Fuel Gas Filter & 91 & 141 & 169.3 \\
\hline Flare Stack & Suction Scrubber & 91 & 135 & 164.9 \\
\hline Flare Stack & Discharge Scrubber & 91 & 113.6 & 176 \\
\hline Flare Stack & Pig Launcher & 91 & 181 & 180 \\
\hline Flare Stack & Condensate Transfer Pump & 91 & 86.8 & 159.7 \\
\hline Flare Stack & Compressor Discharge Cooler & 91 & 104.6 & 109.5 \\
\hline Flare Stack & Lube Oil Cooler & 91 & 113 & 140.7 \\
\hline
\end{tabular}

Table 4. Accounting and PipelineCosts 
Farizal et al., International Journal of Emerging Trends in Engineering Research, 8(6), June 2020, 2465 - 2471

\begin{tabular}{|c|c|c|c|c|c|c|}
\hline \multicolumn{2}{|c|}{ Unit } & \multirow{2}{*}{$\begin{array}{l}\text { Pipe Price/ } \\
\text { Meter } \\
\text { (IDR) }\end{array}$} & \multicolumn{2}{|c|}{ Existing } & \multicolumn{2}{|c|}{ Optimization } \\
\hline From & To & & $\begin{array}{c}\text { Pipe } \\
\text { Length (m) }\end{array}$ & $\begin{array}{l}\text { Piping Cost } \\
\text { (IDR) }\end{array}$ & $\begin{array}{l}\text { Pipe Length } \\
\text { (m) }\end{array}$ & $\begin{array}{l}\text { Piping Cost } \\
\text { (IDR) }\end{array}$ \\
\hline Pig Receiver & Slug Catcher & $3,484,000$ & 42.55 & $148,240,716$ & 14 & $48,776,000$ \\
\hline Slug Catcher & Fuel Gas Filter & 650,000 & 11.96 & $7,771,400$ & 11 & $7,150,000$ \\
\hline Slug Catcher & Suction Scrubber & $3,484,000$ & 15.11 & $52,643,240$ & 12 & $41,808,000$ \\
\hline Slug Catcher & Condensate Drum & 130,000 & 64.79 & $8,423,090$ & 27 & $3,510,000$ \\
\hline Gas Compressor & Suction Scrubber & $3,484,000$ & 29.77 & $103,729,132$ & 32 & $111,488,000$ \\
\hline Gas Compressor & Discharge Scrubber & $1,300,000$ & 27.37 & $35,574,500$ & 58 & $75,400,000$ \\
\hline Gas Compressor & Flare Stack & 130,000 & 145.30 & $18,889,90$ & 162 & $21,060,000$ \\
\hline Discharge Scrubber & Pig Launcher & $1,300,000$ & 75.37 & $97,974,500$ & 40 & $52,000,000$ \\
\hline Suction Scrubber & Condensate Drum & 130,000 & 49.68 & $6,458,790$ & 15 & $1,950,000$ \\
\hline Condensate Drum & $\begin{array}{l}\text { Condensate Transfer } \\
\text { Pump }\end{array}$ & 130,000 & 10.61 & $1,379,040$ & 16.5 & $2,145,000$ \\
\hline Condensate Drum & Flare Stack & 130,000 & 116.80 & $15,184,000$ & 205 & $26,650,000$ \\
\hline Discharge Scrubber & Condensate Drum & 130,000 & 47.33 & $6,153,290$ & 15 & $1,950,000$ \\
\hline \multicolumn{2}{|c|}{ Total Cost } & & & $502,421,088$ & & $393,887,000$ \\
\hline
\end{tabular}

